\title{
COST MODELLING FOR ROOFING MATERIAL SELECTION
}

\author{
R. S. Perera \\ U.L.A.S.B Fernando
}

\begin{abstract}
During recent decades new building techniques have been developed and many new materials have been introduced to the construction market. The material market has become more profitable for contractors and construction material producers than for the client.

Not having being a functional and performance oriented roofing material selection system, domestic clients are in a very tight situation when selecting a suitable roofing material according to their requirement, without they being misled from sales exaggerations.

This paper elaborates preparation of a cost model which can be used for selection of roofing materials for domestic purposes, giving adequate consideration on cost and some other performance factors. Cost comparison of roof covering, ceiling and insulation materials those are available in the Sri Lankan market are investigated along with the other performance factors of materials. Further, the current status of the roof construction and design in the Sri Lankan context is also explained.
\end{abstract}

\section{INTRODUCTION}

Shelter has been one of the three basic needs of human beings ever since evolution. The roof is a main component of any shelter, which gives protection from natural elements and climatic conditions such as sun, rain, wind, heat and cold.

There are many debates over the relative merits of roofing materials selection for domestic construction. The client and designers could not select the most suitable roofing materials for domestic construction due to the fact that they do not have sufficient sources and very little reliable published data in existence.

Having identified the requirement of a cost model to analyse roofing materials; a cost model was developed by analysing some commonly used roof covering, ceiling and insulation materials in terms of cost and some other performance factors. The roof design complexity was adequately taken in to consideration for the purpose of modelling.

This paper describes a cost model for roofing material selection for house construction purposes. A critical review of the literature on cost modelling and the roofing systems is also carried out in this paper. Further performance factors of roofing materials and analysis of roofing cost are also provided.

\section{METHODOLOGY}

Having identified the need for the development of a cost model to select roofing material for house construction a model was developed to provide basic cost and performance information to the user. Since one roof type does not represent all the features of a roof and the fact that the design of a roof affects its cost it was decided to model costs based on three types of designs of varying complexity. These designs represent Simple, Medium complex and Complex types of roofs. Most commonly used rooting materials were selected for comparison purposes. Adequate.consideration was given for roof frame, covering, ceiling, insulation, rainwater goods, painting or polishing of ceiling and all the other cost items that can influence the total cost of the roofing system.

In the Sri Lankan construction industry in practice it is often found that either small-scale contractors or individual craftsmen carry out house construction works (except in the case of large housing schemes and super luxury mansions). In such type of construction it is found that the labour cost is little higher when compared to the large-scale building construction works. Therefore, prevailing labour rates in the domestic labour market in Colombo district were used for the purpose of roof cost calculations. Cost of different roofing systems were estimated separately under few categories viz: Basic cost, Ceiling cost, Insulation cost and Total cost for the benefit of different types of users of the model to select roof covering, ceiling and insulation systems separately, according to their requirements. These are defined as given below.

Basic cost: represents the roof covering, structure, rainwater goods and all the other items of a roof, excluding ceiling and insulation cost.

Total cost: represents the overall cost of the total roofing system (i.e. the cost of structure, covering, ceiling, insulation, rainwater goods and all the other items of a roof. 
Roofing materials were ranked according to the knowledge through literature, observations, interviews with material manufactures, users (house occupants) and by analysing product data.

The subsequent sections of the paper briefly analyses the cost modelling techniques and explains in detail the model construction and the main findings.

\section{INTRODUCTION TO COST MODELLING}

A model can primarily be physical, mathematical or statistical. Cost Modelling is defined as the symbolic representation of a system, expressing the content of that system of the factors, which influence its cost (Ferry \&Brandon, 1991). Brandon (1987) states that the purpose of cost modelling seem to be to provide a reference point where the cost adviser can refer before applying his own experience and to increase understanding and/or predict or influence the future. He further states that the role of a cost model is to predict a future situation and to give an economic dimension to the problem.

According to Ferry and Brandon (1991), a good cost model shall provide better cost information quickly, more in quantity with more reliability at an early stage in the design process and in a more understandable form as possible. Further, using a good cost model shall provide an economic assurance to the client with regard to the cost of his project, and will link the cost control at the design and the construction stages and may be helpful to cost advisers

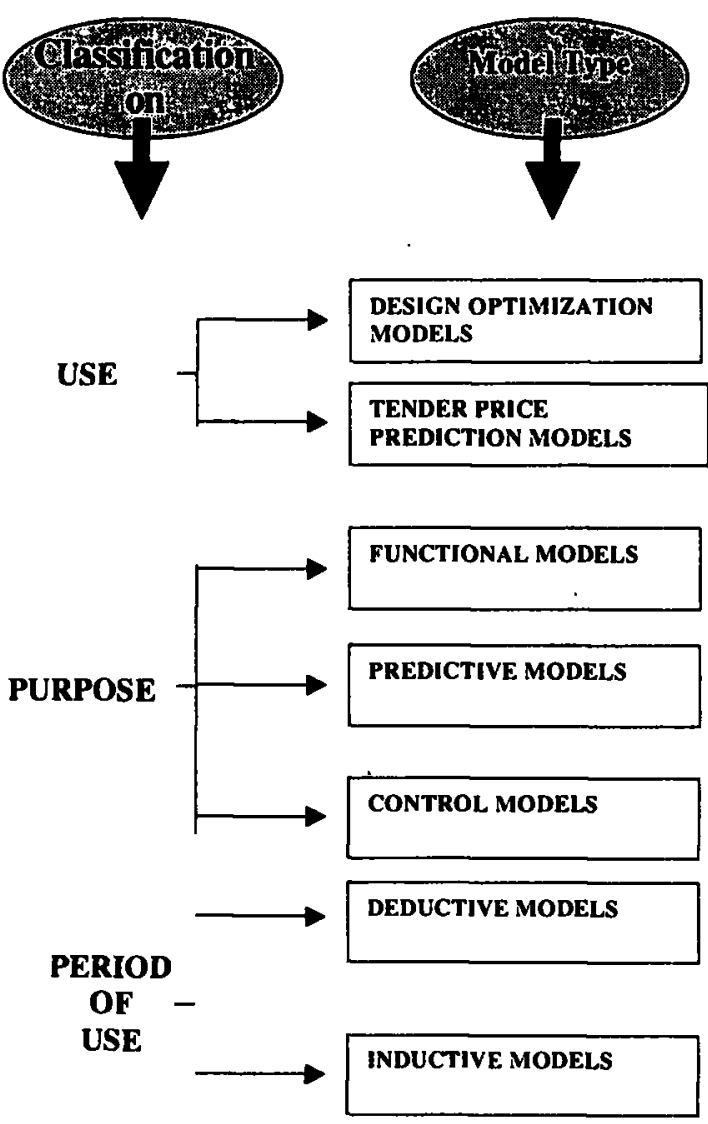

for cost advising purposes and for representation of building in such a way that its cost can be tested and analyzed. A computer integrated cost model shall fulfill most of the above mentioned requirements successfully.

Cost modelling can be classified considering its use, purpose and the stage at which the cost model is used (Refer Figure 1). Several methods can be used for cost modelling purposes as empirical method, Algorithmic methods, Simulation, Heuristics and a combination of these methods.

Emperial models: are symbolic models, which are derived from observation, experience and intuition. They have been developed largely on the basis of "right feeling"(Ashworth, 1982).

Algorithmic methods: are developed using statistical relationship between design variables and cost. Here, the regression analysis technique is used to find a formula or mathematical model (Ferry \& Brandon, 1991).

Simulation method: tries to simulate a series of future events. This method allowes sampling a large number of possible solutions to discover the best solution (Ferry \& Brandon, 1991).

Heuristics: are essencially rule of thumb procedure, which enables a near optimum solution to be produced once the model has been built. These approaches are an attempt to discover the qualities of the expert and to incorporate these into the model (Ashworth, 1982).

Combine methods: are attempts to combine two or more methods identified above into a computer-integrated environment.The selection of most suitable cost modelling technique depends on the requirement of the model to be

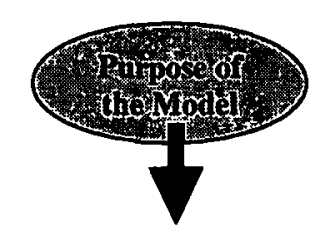

To optimize the value of money of a design

To forecast the likety tender sum

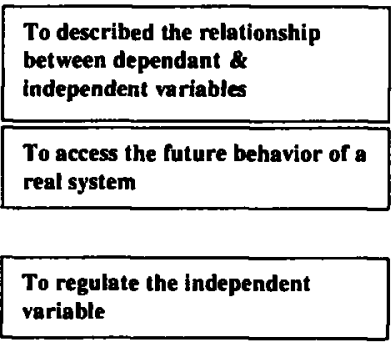

Use at early design stage to forecast the cost using previous performance data

Use at late design stag, to bring contractor's estimate to the design stage.

Figure 1: Cost Modeling 
developed. Drawbacks of traditional cost models have lead to the modem day cost models using combined methods and knowledge based systems.

\subsection{DEVELOPING A COST MODEL FOR ROOFING MATERIAL SELECTION}

\subsubsection{The Need of a Cost Model}

Having abundance of material options for roof covering, insulation and ceiling materials in the construction market, selection of materials according to requirement has been a difficult task for domestic client as well as for construction professionals. There is hardly much product information available at hand to the domestic client or to the construction professionals to advise a building client. Information available is piece meal and hardly any comparative analysis available. Therefore, it is obvious that there should be a proper advisory system to select the most suitable materials that best satisfy client requirements in order to gain the maximum benefits.

\subsubsection{Advantages of Having a Cost Model for Roofing Material Selection}

Developing a cost model to select roofing materials for domestic purposes will provide numerous advantages to domestic clients, designers and cost advisors in various ways. The cost model will be helpful to select suitable roofing materials giving adequate consideration on cost factors as well as for other performance factors like thermal performance, water tightness etc.

- The cost model will be helpful to get a decision of suitable roofing material by giving consideration on cost factors as well as for other performance factors like thermal performance, etc.

- By having the model a laymen shall not need to depend on sales exaggerations. He will be able to form an independent decision on selection of roofing materials.

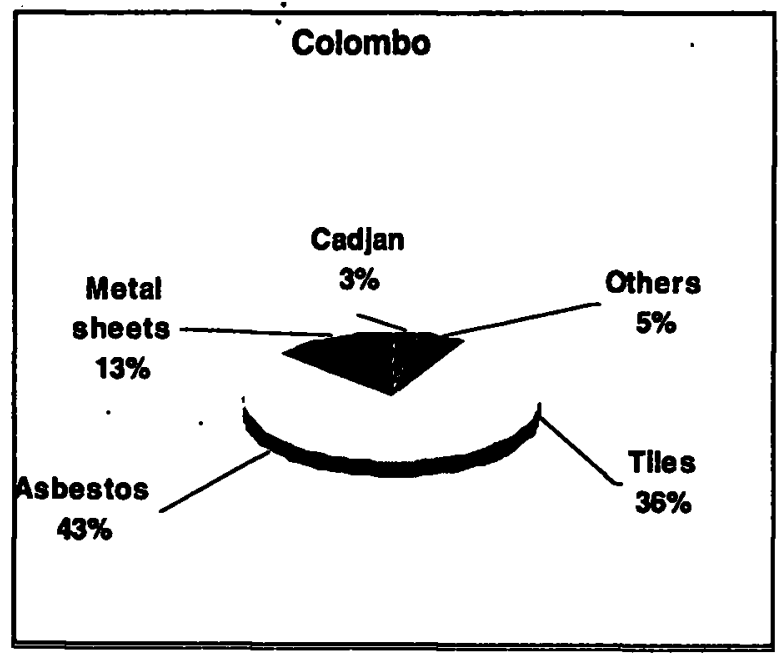

Source : Demographic Survey 1994, Release 4
- The designers and cost advisors shall put adequate consideration on cost factors when selecting a suitable roofing system for domestic purposes.

- The client and cost advisors shall be aware of allinclusive average cost figure for a roofing system.

\section{THE ROOF}

Roof is the building element most exposed to the climatic conditions. The impact of solar radiation, loss of heat by long wave radiation during the night, the rain, and other climatic elements affect the roof more than any other part of the structure (Givoni. B, 1976). The primary function of the roof is to protect the inside of the building from the hostile elements (Lakshman K. D. 1992). Break up of elemental cost shows that the roof cost takes a considerable portion of total cost of a house construction. It is approximately 10-20percentage of the total cost (Perera J, 1992). The roof is one of the main elements exposed to the out side. Consequently its contribution to the aesthetics of a house is also greater. Therefore, to make the house more attractive, it is often required to have an attractive roof.

The roof is not a contemporary product, but it is a result of many experiments and experiences (Lakshman, 1992). New roof systems have been introduced from time to time with additional features like greater thermal comfort, less cost, greater durability, easy of fixing, greater weather tightness and many other aspects of performance to satisfy the requirements of the customer (Coates, 1993).

The uses of roof covering materials are subjected to change from time to time. A greater part of roofs in Sri Lanka had been constructed using cadgen in the early days and it has now gradually converted wards the use of more durable materials. Figure 2 below shows the usage of roofing materials within Sri Lanka by year 1994. Usage of Asbestos cement sheets is more common within the city of the country and Calicut tiles in rural areas.

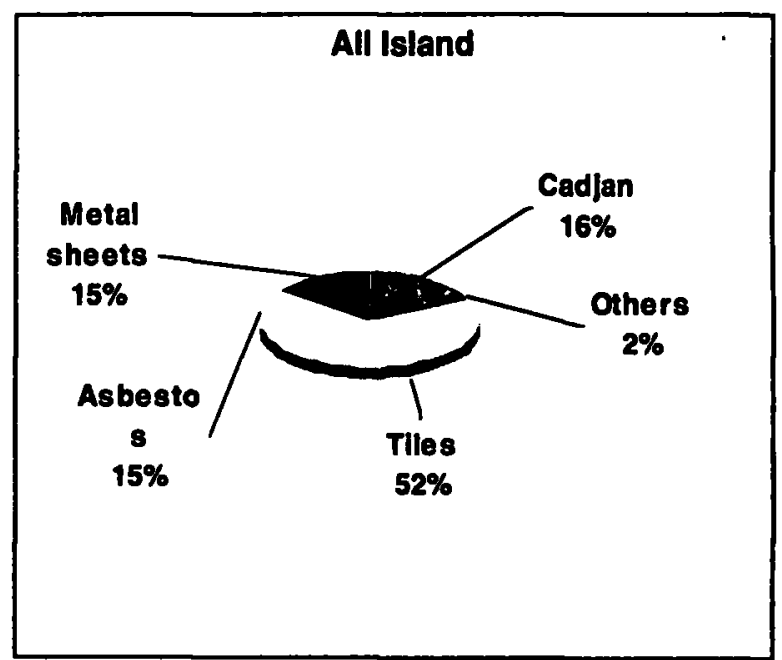

Source : Demographic Survey 1994, Release 2

Figure 2: Roof Material Use in Sri Lanka 


\subsection{ROOFING MATERIALS}

The roof is basically a combination of several major components as shown in the table No 1. In order to have a comfort living condition inside a house and to construct the roof economically, selection of proper combination of roof covering, roof structure, ceiling and insulation material is essencial.

Table 1: Materials used for roofing components in Sri Lanka

\begin{tabular}{|l|l|}
\hline Roof Component & \multicolumn{1}{|c|}{ Available Materials in Sri Lankan Market } \\
\hline Roof covering & $\begin{array}{l}\text { Cadjan, G.I sheets, Half round clay tiles, Calicut tiles, Asbestos cement sheet, } \\
\text { Colorcon tile, Micro Concrete Roof tiles (MCR), Zn /Al sheet, Coir fiber cement } \\
\text { sheet, Reinforced concrete deck. }\end{array}$ \\
\hline Roof frame & Timber - Red ballow, Kampus, Mee, Tualang, etcSteel Reinforce concrete \\
\hline Roof insulation & $\begin{array}{l}\text { Glass wool ( 16Kg /m3 or 24Kg/m3, 25mm thick) with single side } \\
\text { Al foil } \\
\text { Double side Al foil } \\
\text { Polyuthaleen (3,8,12mm thick) } \\
\text { Polystrene ( for flat roofs) } \\
\text { Regiform (for flat roofs) }\end{array}$ \\
\hline Ceiling & $\begin{array}{l}\text { Timber (Lunumidella, Pine wOOd) } \\
\text { Plywood sheets } \\
\text { Asbestos ceiling sheets } \\
\text { Hawood plastic ceiling panels. }\end{array}$ \\
\hline Rainwater goods & PVC, Zn / Al, G.I \\
\hline Water proofing & $\begin{array}{l}\text { Sheet applications - ECOGUM, DESERT SHIELD MEMBRANCES } \\
\text { Liquid applications - SHIELDKOTE, ROOFTEX }\end{array}$ \\
\hline
\end{tabular}

Out of various roof covering insulation and ceiling materials, most commonly used materials in Sri Lanka are selected for detailed analysis. Selected materials for the detail analysis are;

Roof covering materials : Calicut tiles, Asbestos cement sheet, Colorcon tile, Micro Concrete Roof tiles, $\mathrm{Zn} / \mathrm{Al}$ sheet, Reinforced concrete deck.

Insulation materials : Glass wool, Double side Al foil, Polyethylene, Polystyrene.

Ceiling materials : Timber, Plywood sheets, Asbestos ceiling sheets

\subsection{PERFORMANCE OF ROOFING MATERIALS}

Clients basically raise certain common questions, when purchasing or deciding to use roofing material for their houses; as whether the material fulfil the requirement of thermal comfort, water tightness, noise control, durability, easy to maintain and erection, aesthetic appearance, strength, protection from health hazards and economy. In most of the cases, out of all aforementioned factors much more consideration is given for thermal comfort level, water tightness, economy and aesthetic appearance; and priority depends on the qualities of the client like their income level, complexity of house that he required etc. These factors are analyzed in detail in the following sub sections.

\subsubsection{Thermal Comfort}

Roof modifies the internal temperature, when appropriate properties are chosen. It will be possible to achieve and maintain comfortable internal temperature over a wide range of external conditions (Lakshan, 1999). The roof is the only element, which is unprotected against the radiant heat load from the sun. Increase in the temperature of the ceiling is transmitted to the occupants of the room mainly by radiation as shown in the Figure 3 below.

Figure 3 Proportion of heat flowing down wards from ceiling

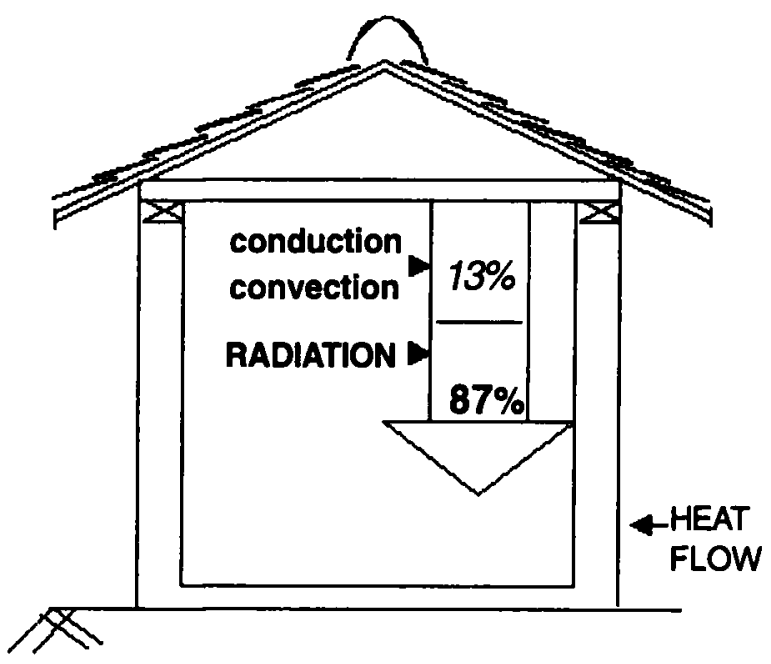


To be satisfactory a roof must therefore, absorb as little radiant heat as possible and offer almost complete resistance to heat flow from the outside to the inside (Koenigsberger .0,1965). The factors that may influence the thermal performance of the roof are (Giovni. B, 1976);

a) The thermal resistance of the roofing materials.

b) External surface colour.

c) Ventilation of the attic space.

d) The ceiling height.

A house to be thermally comfortable, the roof should be designed to have " $U$ " value below 1.5BTU. Lakshan, (1999) ranks some roofing materials available in the $\mathrm{Sri}$ Lankan market according to the outcomes of a laboratory test which was carried out to test the thermal performance.

Table 2 : Roof covering materials rank on thermal performance

\begin{tabular}{|l|c|}
\hline \multicolumn{1}{|c|}{ Roof Covering Material } & Rank \\
\hline Asbestos with covering tiles & 1 \\
\hline Calicut tiles & 2 \\
\hline Asbestos with whitewash & 3 \\
\hline Asbestos & 4 \\
\hline $\mathrm{Zn} / \mathrm{Al}$ & 5 \\
\hline
\end{tabular}

Figure 3: Thermal Performance of Roofing Materlals

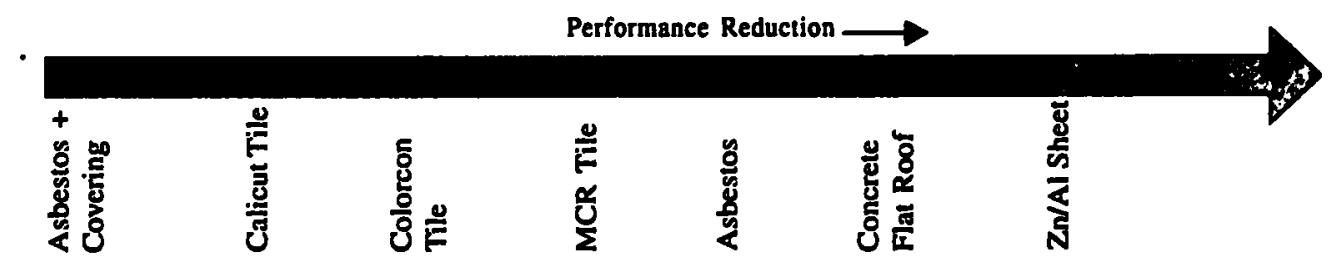

\subsubsection{Water Tightness}

Table No 03 - Water Tightness of Different Roofing Materials

\begin{tabular}{|c|c|}
\hline Calicut Tile & $\begin{array}{l}\text { Provide the lowest water tightness, due to not having proper end and side interlocking } \\
\text { and high water absorption rate. }\end{array}$ \\
\hline Colorcon Tile & $\begin{array}{l}\text { The water absorption rate is low with comparison to Calicut and MCR tiles due to } \\
\text { having a smooth external surface-waterproofing layer. } \\
\text { End and side interlocking are better than the Calicut and MCR tiles. }\end{array}$ \\
\hline MCR Tile & $\begin{array}{l}\text { Having external smooth surface the water absorption is little lower, but not as low as } \\
\text { Colorcon tile. }\end{array}$ \\
\hline Asbestos \& $\mathrm{Zn} / \mathrm{Al}$ & $\begin{array}{l}\text { Being sheet materials provides best water tightness } \\
\text { Water absorption is very low. }\end{array}$ \\
\hline Concrete Flat Roof & $\begin{array}{l}\text { Concrete not being a waterproof material, additional waterproof layer is needed } \\
\text { to prevent water absorption and leakage. } \\
\text { The water tightness shall depend on the quality of workmanship and the type } \\
\text { of waterproofing materials. }\end{array}$ \\
\hline
\end{tabular}


Figure 4: Water Tightness of Roofing Materials

Performance Reduction $\longrightarrow$

\begin{tabular}{|c|c|c|c|c|c|}
\hline 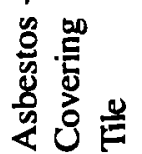 & $\underset{\mathfrak{S}}{\overleftarrow{S}}$ & $\begin{array}{l}\tilde{y} \\
\frac{8}{8} \\
\frac{8}{z}\end{array}$ & $\begin{array}{l}\frac{5}{8} \\
\frac{0}{0} \\
0\end{array}$ & 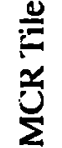 & 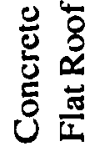 \\
\hline
\end{tabular}

\subsubsection{Durabillty and Maintenance}

Table 4: Durability And Maintenance of Different Roofing Materials

\begin{tabular}{|c|c|}
\hline Calicut tiles & $\begin{array}{l}\text { There is a high possibility for calicut tiles to get damaged, so replacing of tiles } \\
\text { from time to time is needed. } \\
\text { Fungus are grown on tiles, so, periodical cleaning is needed. }\end{array}$ \\
\hline Colorcon tiles & $\begin{array}{l}\text { Cleaning of tile is needed to maintain the appearance and thermal properties of } \\
\text { the roof. }\end{array}$ \\
\hline Asbestos sheet & $\begin{array}{l}\text { External surface becomes dull gray colour, so, periodical painting is needed to } \\
\text { maintain the thermal properties and the appearance. } \\
\text { If white washed on roof surface to get thermal performance. re-painting is required } \\
\text { at least once in two-years. }\end{array}$ \\
\hline $\begin{array}{l}\text { Asbestos with } \\
\text { covering tiles }\end{array}$ & $\begin{array}{l}\text { Covering tiles are subject to slip over the time, so. periodical re-arrangement of } \\
\text { covering tile is needed. }\end{array}$ \\
\hline MCR tiles & $\begin{array}{l}\text { Color tiles are subjected to discolour, therefore re-painting is required once in five } \\
\text { years time. } \\
\text { There is a possibility for growing of fungus on colour-less tiles. }\end{array}$ \\
\hline $\mathrm{Zn} / \mathrm{Al}$ & $\begin{array}{l}\text { Damage to outer coat during transport and erection lead to corrosion of the base } \\
\text { material. } \\
\text { Regular cleaning of surface by hosing and removal of debris is essential to preve } \\
\text { nt corrosion. } \\
\text { There is high possibility to corrode the cladding in corrosive environment like co } \\
\text { astal areas. }\end{array}$ \\
\hline $\begin{array}{l}\text { Concrete flat } \\
\text { roof }\end{array}$ & $\begin{array}{l}\text { Reinforced concrete is usually of excellent durability provided adequate care is } \\
\text { taken with the design mix, choice of ingredients, mixing, placing, compacting } \\
\text { and curing.Further, the care must be taken to provide adequate clear cover and } \\
\text { proper waterproofing system.(Sperling } . R, 1987 \text { ) }\end{array}$ \\
\hline
\end{tabular}

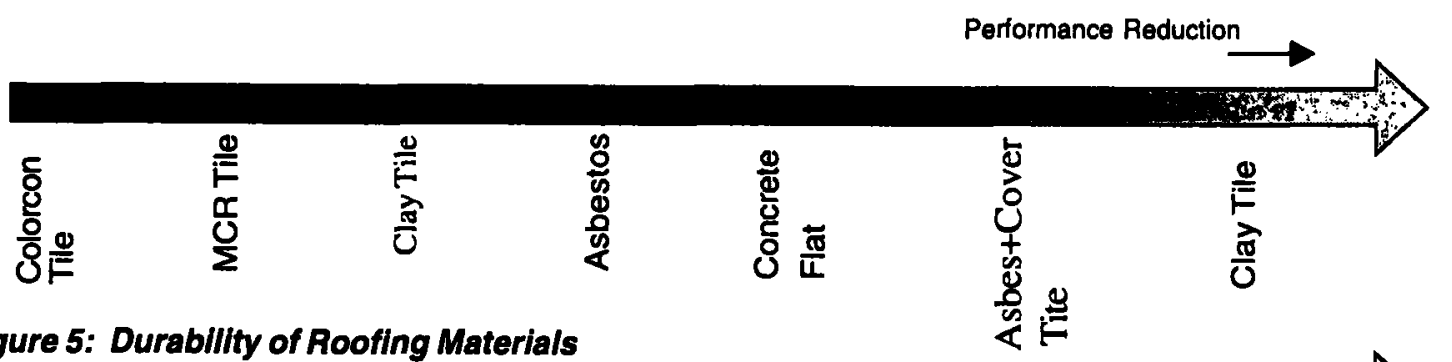

Figure 5: Durabllity of Roofing Materials

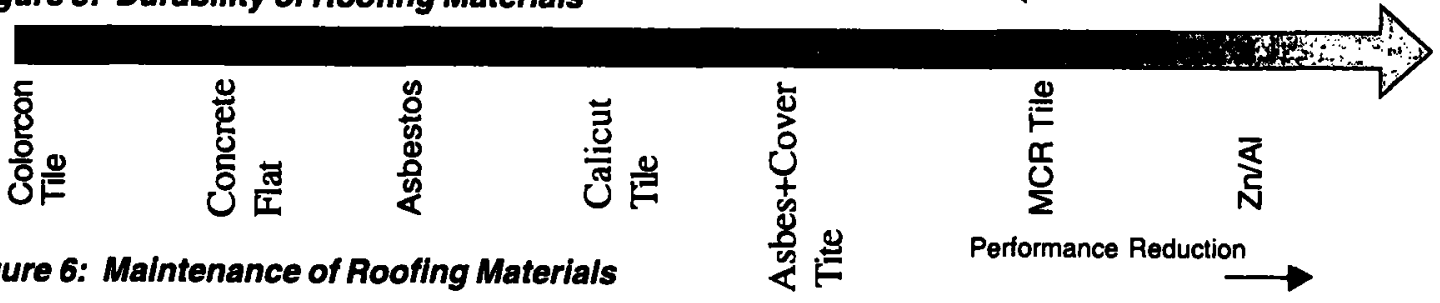




\subsubsection{Erection, Strength and Weight}

Table 5: Erection, Strength and Weight of Different Roofing Materials

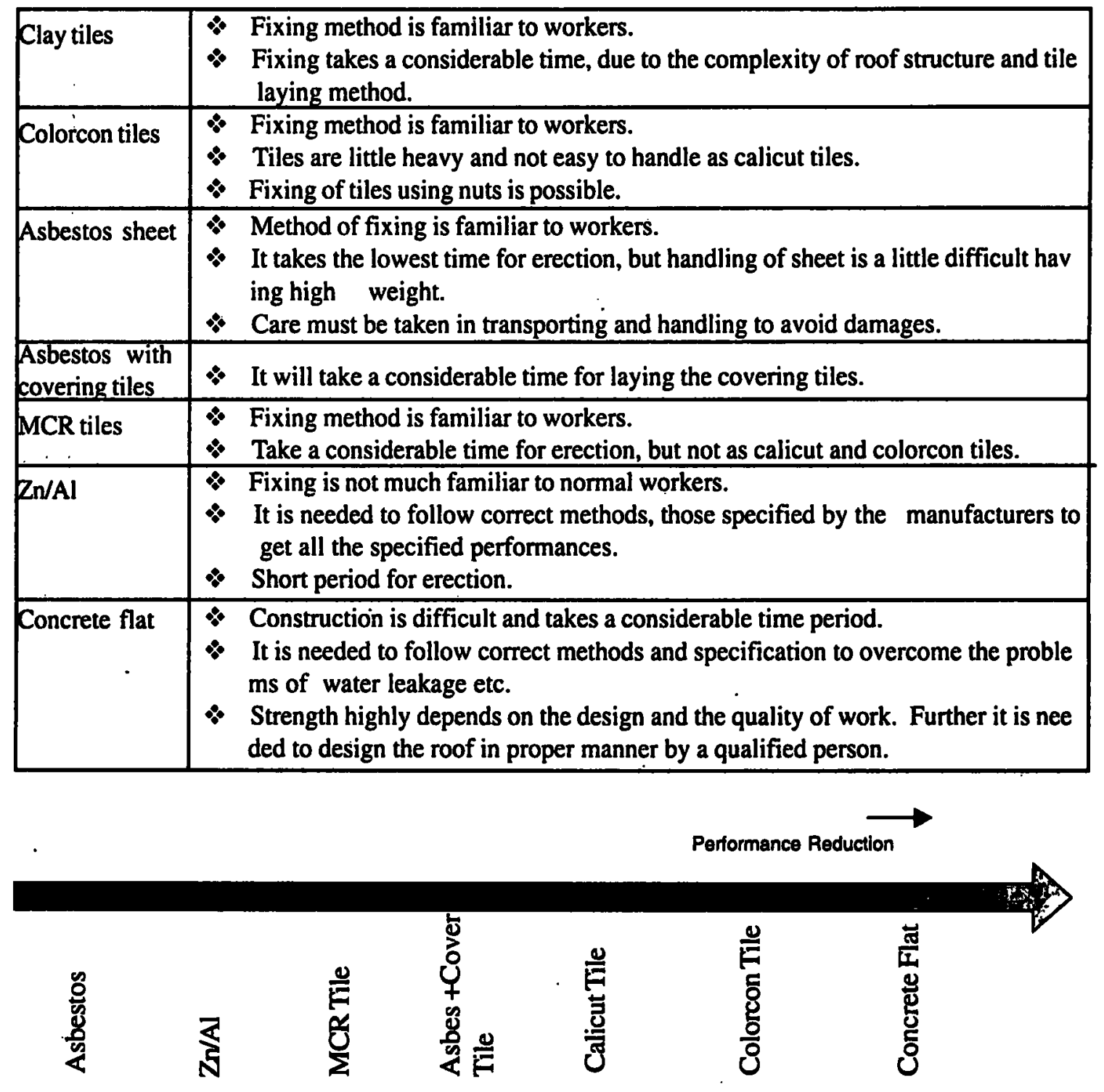

Figure 7: Erectlon of Roofing Materials

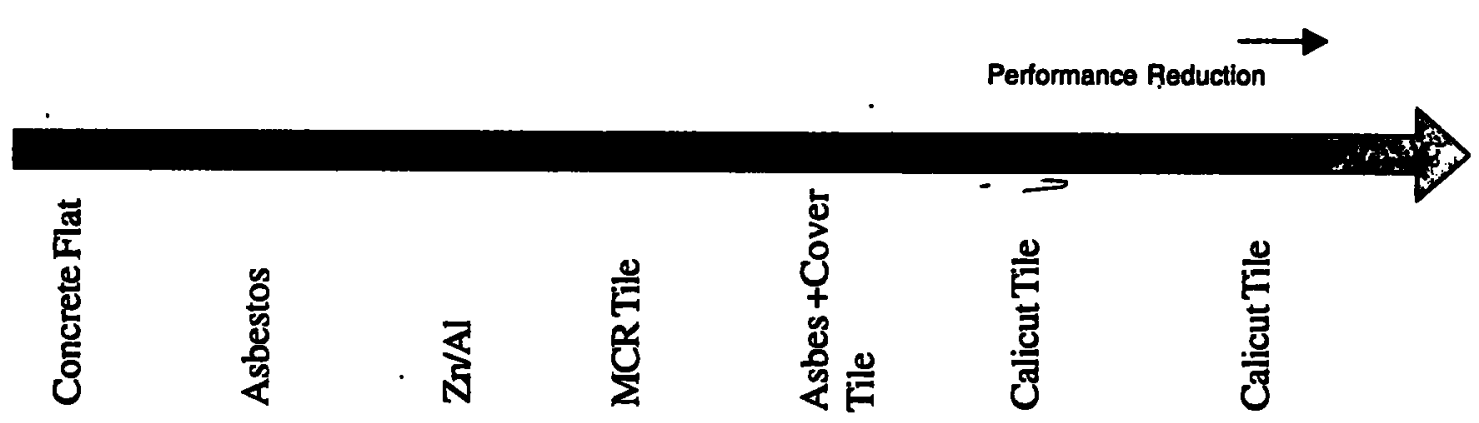

Figure 8: Strength of Roofing Materials 


\subsubsection{Availability}

\section{Table 6: Availability of Different Roofing Materials}

\begin{tabular}{|c|c|}
\hline Calicut tile & $\begin{array}{l}\text { Availability is little low in Colombo area, but commonly used in rural areas } \\
\text { There are no options for colours and different sizes. }\end{array}$ \\
\hline Colorcon tile & $\begin{array}{l}\text { Availability is limited. } \\
\text { Different colour tiles are available, but no options for size. }\end{array}$ \\
\hline $\begin{array}{l}\text { Asbestos } \\
\text { sheet }\end{array}$ & $\begin{array}{l}\text { Available almost at every hardware within Colombo area, but it is not so in out } \\
\text { side villages. } \\
\text { Few options for sheet sizes }\left(6^{\prime}, 8^{\prime}, 10^{\prime}, 12^{\prime}\right) \text { and being large size sheets the wastage } \\
\text { is high when using for complex type roofs. } \\
\text { No option for colours. }\end{array}$ \\
\hline $\begin{array}{l}\text { Asbestos with } \\
\text { covering tile }\end{array}$ & * Availability of covering tile is very limited within Colombo area. \\
\hline MCR tiles & $\begin{array}{l}\text { Availability is very limited due to not having a considerable number of manufacturers } \\
\text { in the country. } \\
\text { Available in two sizes. }(600 \times 600 \& 500 \times 250 \mathrm{~mm}) \text { and also available in any colours. }\end{array}$ \\
\hline $\mathrm{Zn} / \mathrm{Al}$ & $\begin{array}{l}\text { Available only from manufacturers and there are considerable number of manufactures } \\
\text { within the Colombo District. } \\
\text { Purchasing of any cut length ( up to } 12 \mathrm{~m} \text { length) and various colour sheets possible. }\end{array}$ \\
\hline Concrete flat & $\begin{array}{l}\text { All required materials are normally available in the market other than waterproofing } \\
\text { and insulation materials. }\end{array}$ \\
\hline
\end{tabular}

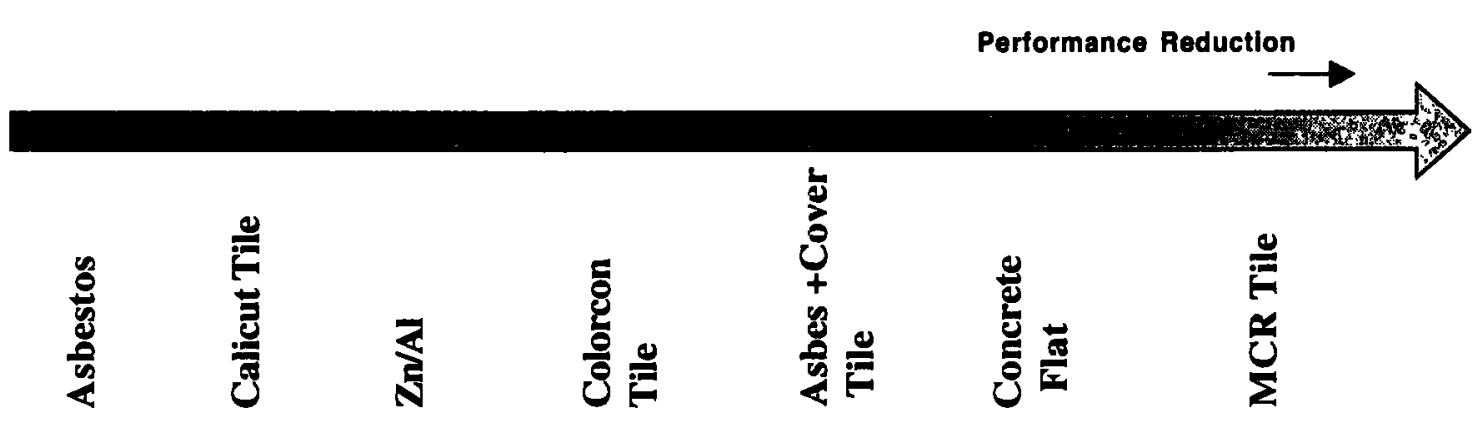

Figure 9: Availability of Roofing Materials

\subsubsection{Health Hazard}

None of the roofing materials other than Asbestos cement sheets have been suspected as affecting the health of habitants. Asbestos cement sheet are made up of microscopic fibres which, when inhaled in its pure form may constitute a serious health risk. It is associated with two debilitating and terminal illnesses namely, lung cancer and asbestosis (Taylar, 1994). However, the Asbestos roofing and ceiling sheets are widely used in Sri Lanka. There are no records, research nor conclusive proof of any ill effects of the use of asbestos roofing products found in Sri Lanka. Reasons for this may be that the low or minimum quantity of asbestos fibres being used along with a high proportion of cement in the asbestos products manufacturing process.

\subsection{ROOFING MATERIAL COST}

The roof cost not only changes according to the type of roofing material used but also according to the design of the roof. Three different roof designs as simple, medium complex and complex those represent pitched roof, hip roof and roof consist of several levels respectively were selected for the analysis. Basic cost, ceiling, insulation costs and cost of total roofing systems are shown separately. Basic costs represent the cost of roofing systems excluding ceiling and insulation costs. 


\subsubsection{Basic Cost of a Simple Type Roof}

It was found that in terms of basic cost of a simple type roof, the Asbestos roofing system cost was the lowest. It was due to its less material requirement for the construction of the frame and low labour cost. Cost of Asbestos roofing system is $11 \%, 21 \%, 27 \%, 29 \%$ and. $42 \%$ lower than the MCR non-colour tile $(600 \times 600 \mathrm{~mm})$, Asbestos with covering tiles, $\mathrm{Zn} / \mathrm{Al}$ CORRODEC, Calicut tiles and Colorcon tiles respectively.

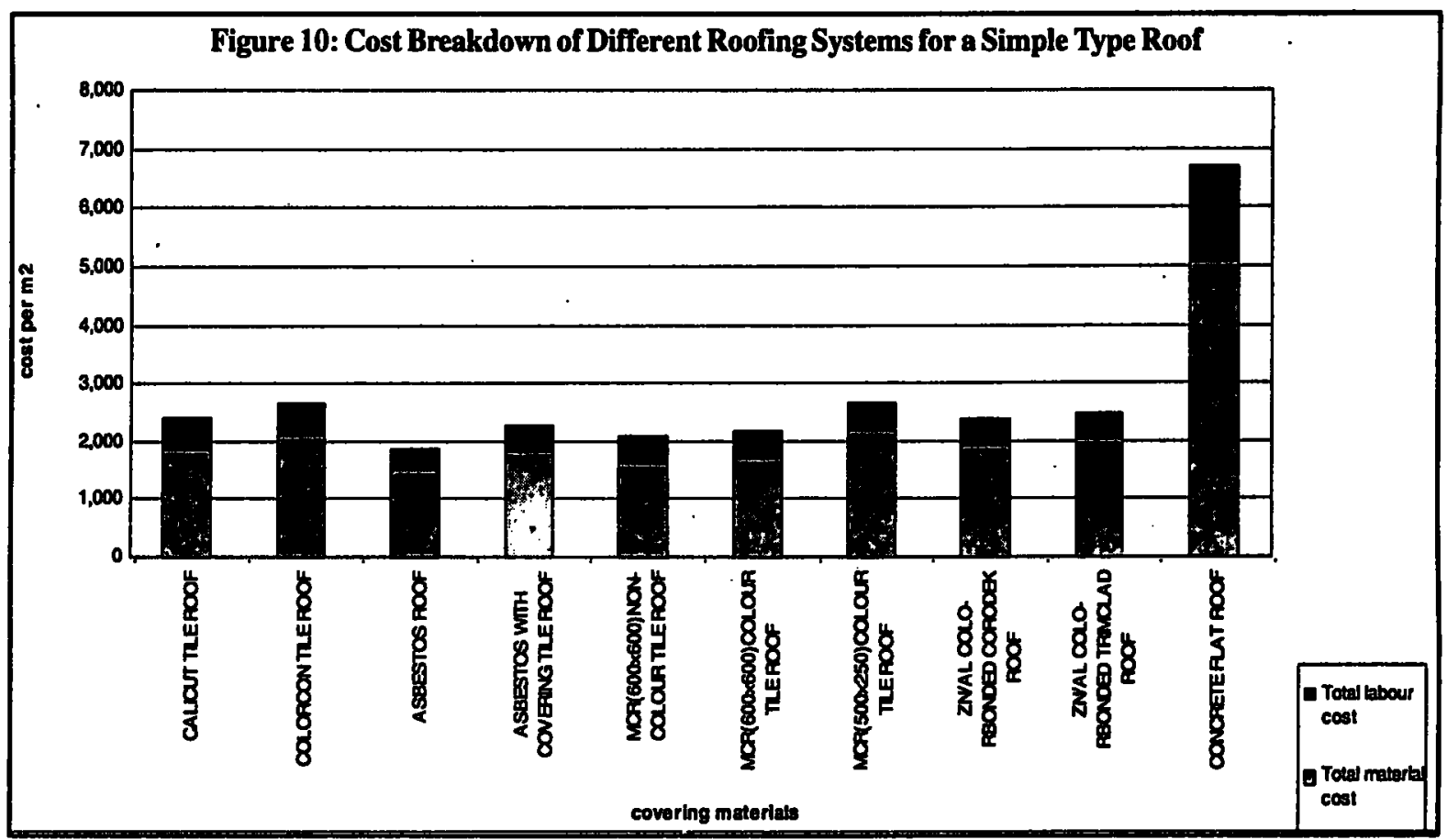

\subsubsection{Basic Cost of a Medium Complex Type}

\section{Roof}

Asbestos roofing system being the least cost option provides cost saving of $8 \%, 17 \%, 21 \%, 34 \%$ and $37 \%$ over the MCR (600x600mm) non-colour, Asbestos with covering tile, Calicut tile, ZN/AI CORRODEC and Colorcon tile respectively.

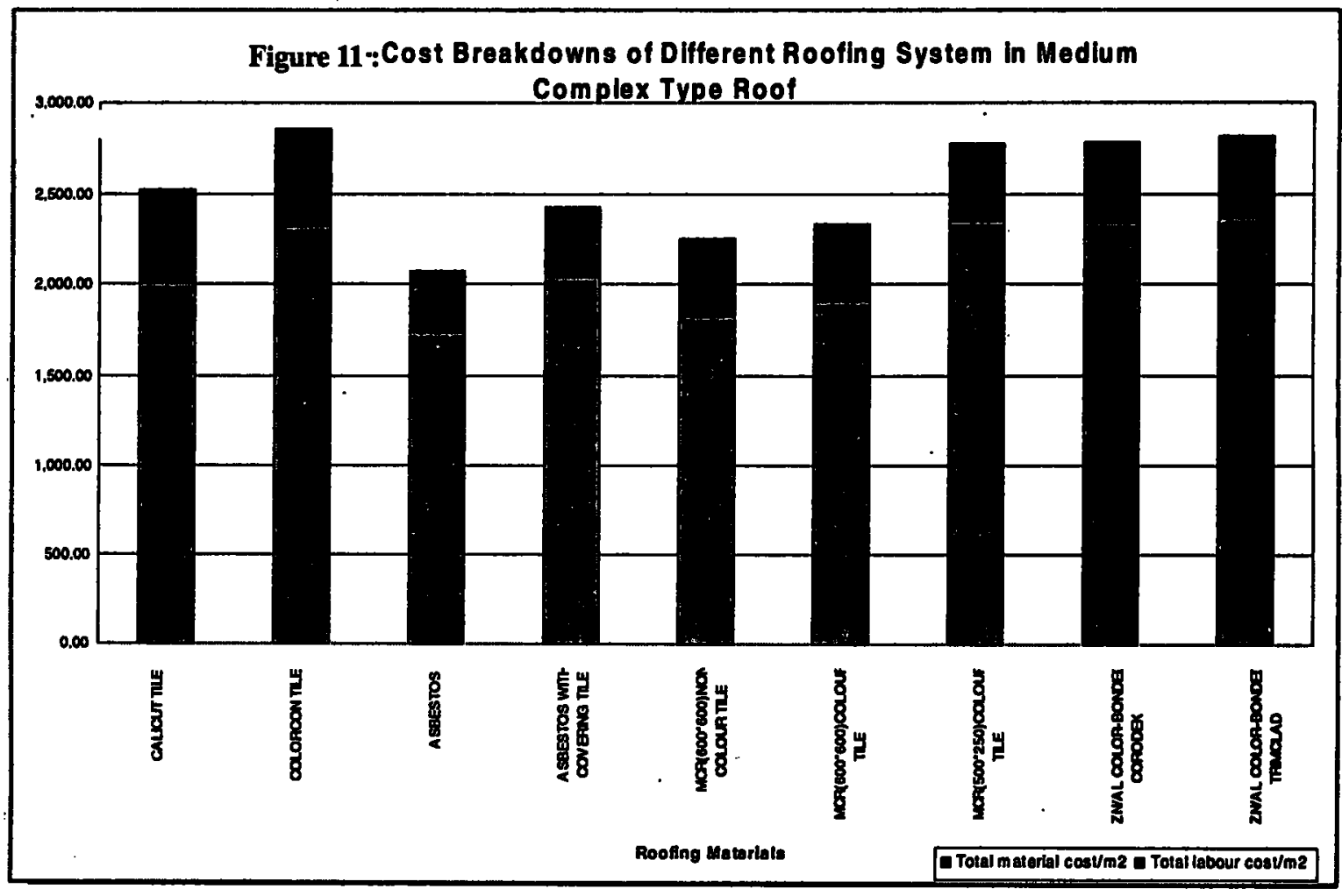




\subsubsection{Basic Cost of a Complex Type Roof}

Asbestos roofing system gives the lowest cost system even for a complex type roof. It is approximately 3percentage, 12percentage, 17percentage, 18percentage and 28percentage lower than the MCR $(600 \times 600 \mathrm{~mm})$ non-colour, Asbestos with covering tiles, Calicut tile Zn/AI CORRODEC and Colorcon tile respectively.

\subsubsection{Ceiling Cost}

Selecting a ceiling type is commonly based only on cost of ceiling material without giving adequate consideration on additional requirements like painting, polishing, labour cost, additional brick work plastering at gable ends particularly in sloping ceilings. Costs of Asbestos and Plywood sheet ceiling are somewhat identical and considerably lower than Lunumidella timber ceiling. Further, it is found that a significant cost saving can be achieved by constructing a rafter exposed Asbestos ceiling with an Asbestos sheets covered roof.
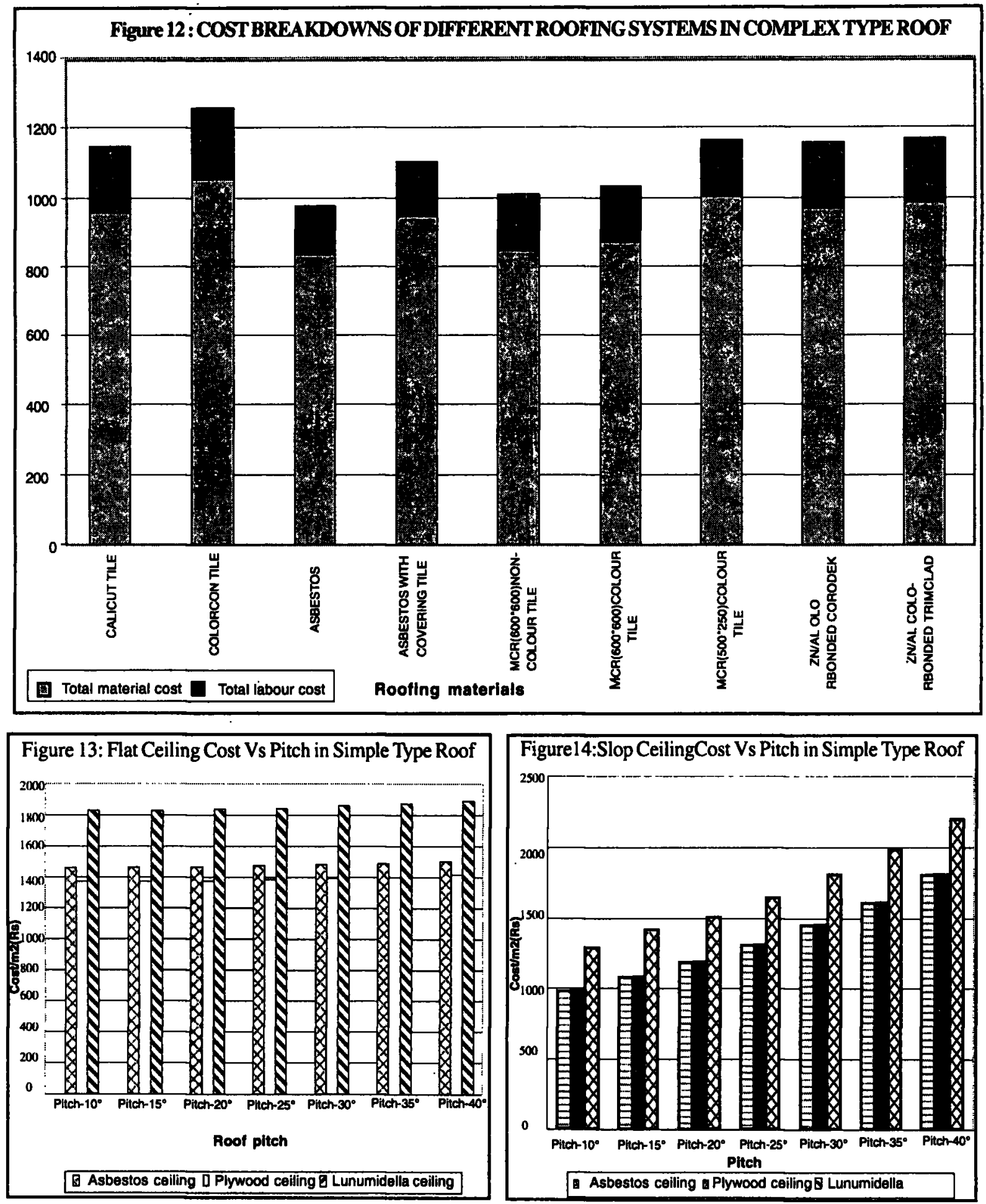

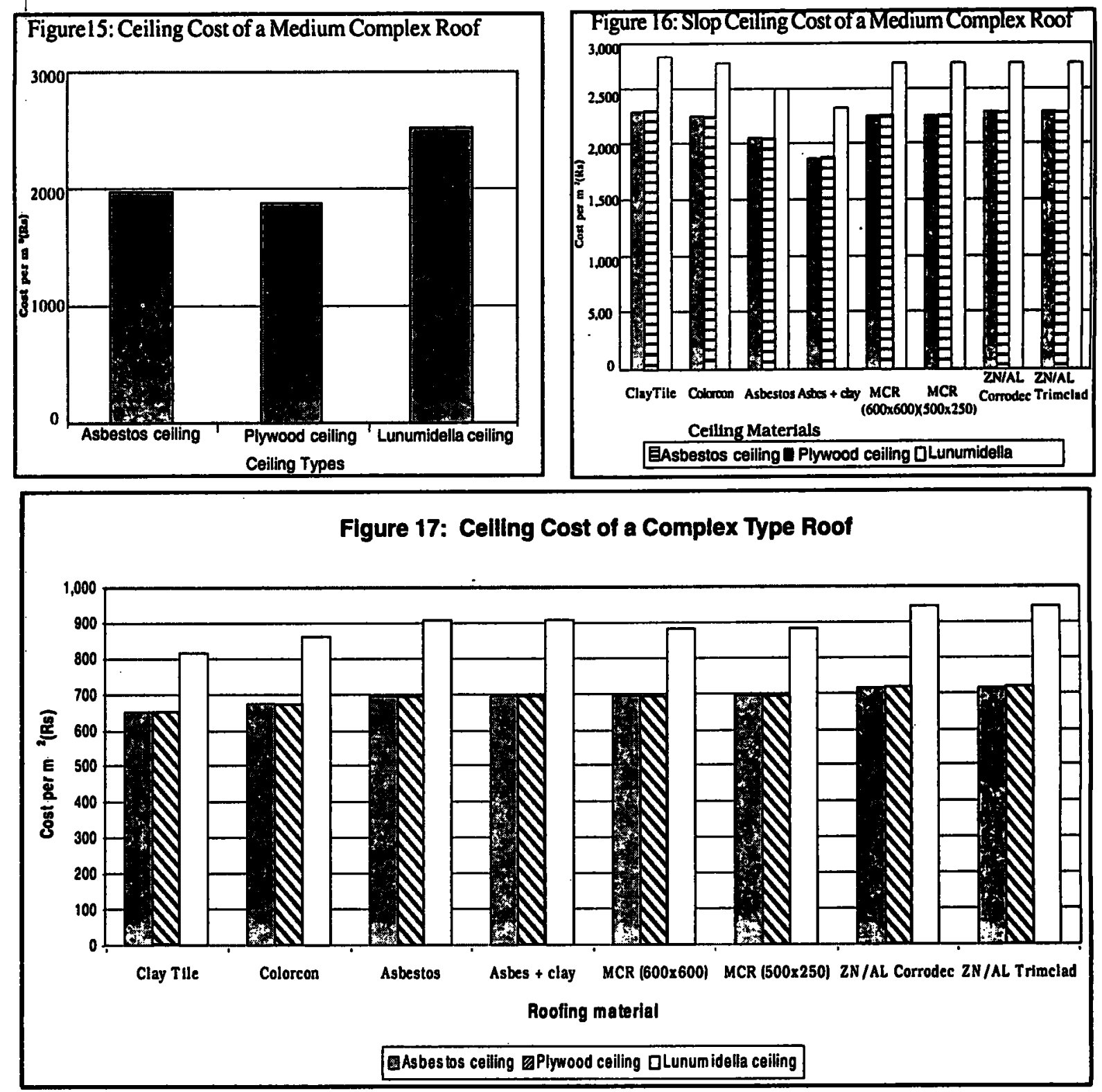

\subsubsection{Insulation} Cost

Figure 18: Insulation Cost vs. Pitch - Simple Type Roof

$3 \mathrm{~mm}$ thick

Poluthaleen is the least cost

insulation material for all.roof types. Roof pitch highly influence the insulation cost. As shown in Figure 18 insulation cost increases significantly with roof pitch. It was found that insulation cost increases by about $28 \%$ for a roof pitch change from $10^{\circ}$ to $40^{\circ}$.

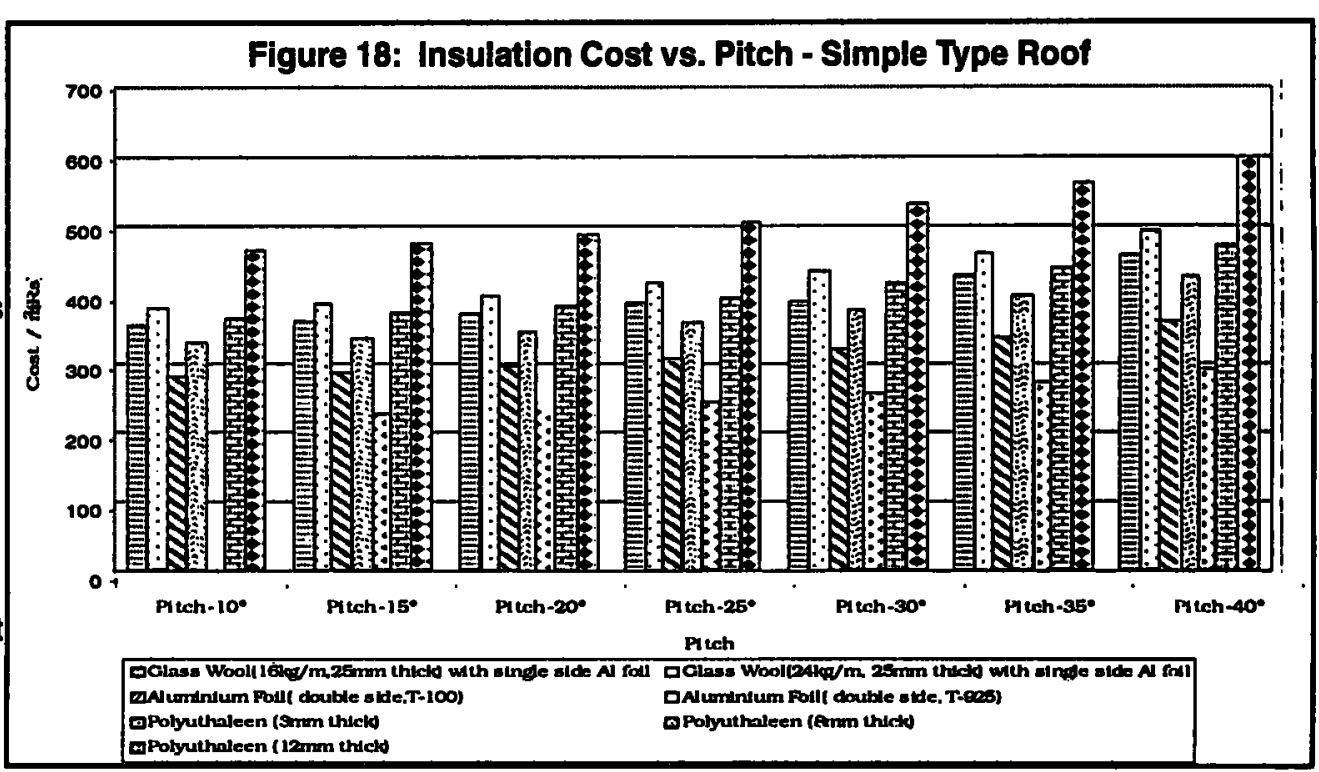



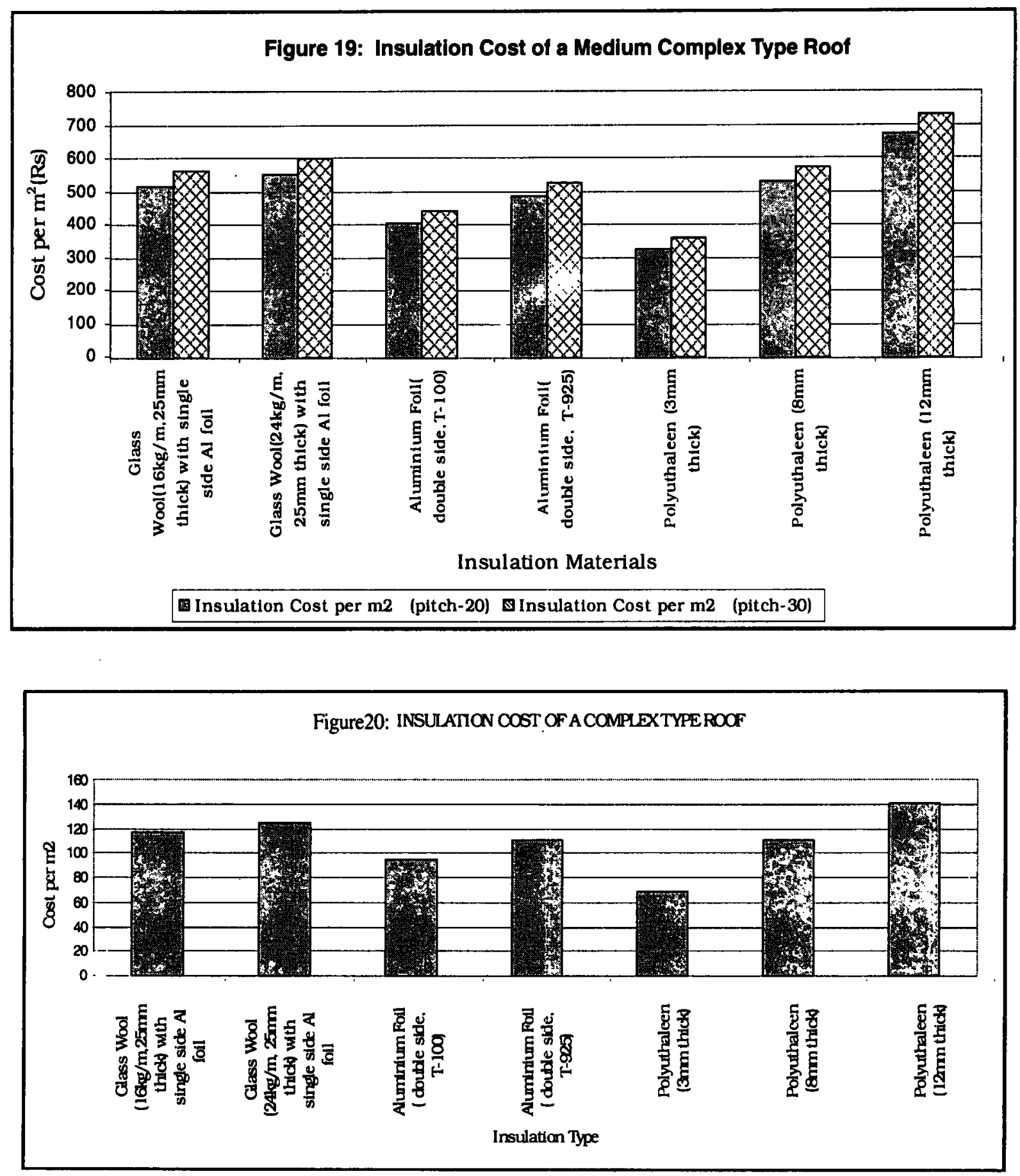

\subsubsection{Total Roof Cost}

The total roof cost refers to the total of basic roof cost, ceiling cost and insulation costs. Different roof covering, ceiling and insulation material combinations gives different total roof costs for different roof designs. Analysis of total roof cost shows that the lowest cost combination (total cost) for all simple, medium complex and complex type of roof design is given by the Asbestos roof covering with slope rafter exposed asbestos ceiling and $3 \mathrm{~mm}$ thick Poluthaleen insulation. 
Table 7: Summary of Roofing Material Performance

\begin{tabular}{|c|c|c|c|c|c|c|c|c|c|c|c|c|c|}
\hline $\begin{array}{c}\text { ROOFING } \\
\text { MATERLAL }\end{array}$ & 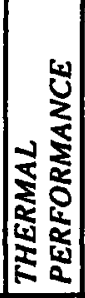 & 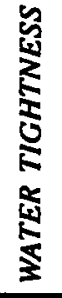 & $\sum_{2}^{\infty}$ & 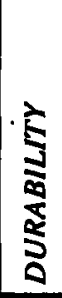 & 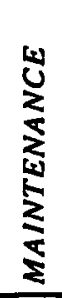 & 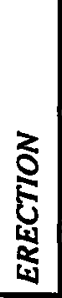 & 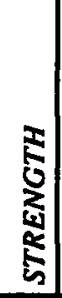 & 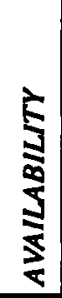 & 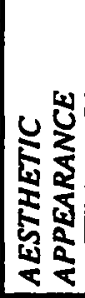 & 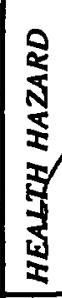 & 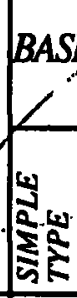 & 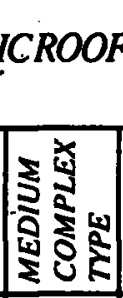 & 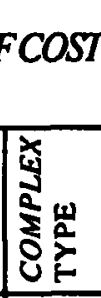 \\
\hline CLAY TLE & 2 & 7 & 2 & 3 & 4 & 5 & 6 & 2 & 5 & 1 & 5 & 4 & 4 \\
\hline COLORCON & 3 & 5 & 2 & 1 & 1 & 6 & 7 & 4 & 1 & 1 & 6 & 6 & 6 \\
\hline ASBESTOS & 5 & 3 & 2 & 4 & 3 & 1 & 2 & 1 & 6 & 2 & 1 & 1 & 1 \\
\hline $\begin{array}{l}\text { ASBESTOS WITH } \\
\text { COVERING TILE }\end{array}$ & 1 & 2 & 2 & 6 & 5 & 4 & 5 & 5 & 4 & 2 & 3 & 3 & 3 \\
\hline $\begin{array}{l}\text { MCR600x600(non- } \\
\text { colour) }\end{array}$ & 4 & 6 & 2 & 2 & 6 & 3 & 4 & 7 & 3 & $\mathbf{1}$ & 2 & 2 & 2 \\
\hline ZNAL & 7 & 1 & 3 & 7 & 7 & 2 & 3 & 3 & 2 & 1 & 4 & 5 & 5 \\
\hline CONCRETE FLAT & 6 & 4 & 1 & 5 & 2 & 7 & 1 & 6 & 7 & 1 & 7 & - & - \\
\hline
\end{tabular}

NOTE - Number 1 represents the best performance.

\section{CONCLUSION}

The break up of total cost of a building in to elements shows that the roof takes a considerable portion of the total cost of a house construction. This ranges from 10 percentage to 20 percentage of total cost.

The roof is the building component most exposed to the climatic elements. Experiences and experiment on roof performance factors such as cost, durability, thermal performance, etc lead to the improvement of the living condition inside a house. New roofing materials are being introduced to the materials market. The use of Asbestos cement sheet is becoming popular in the Colombo district, whereas in most of other district calicut tiles are still widely used.

When analyzing roofing materials on its performance it become evident that none of roofing materials perform to the highest levels. The importance of performance factors differs from one person to another and is govemed according to the client requirements and their income levels. However, thermal comfort, water tightness and economy were identified as performance factors considered important by the majority.

Asbestos cement roofing system was to be found to be having lowest cost over all the other roofing systems considered in each of simple, medium complex and complex type roof designs. It was found that the cost of using other materials reduces considerably with increase of design complexity of the roof. This can be seen as one of main factors to consider in designing roof and selection of roofing systems by the architects.
Another important factor that came in to light was that the cost of Asbestos and Plywood ceiling appears to be identical and is considerably lesser when compared with traditional timber paneled ceiling (eg:- Lunumidella). Further, the use of the method of exposed rafters for ceilings reduces the structural cost of ceilings considerably with a net saving of percentage over traditional flat ceilings.

The use of $3 \mathrm{~mm}$ thick Polyuthaleen provides thermal insulation of a roof at a lower cost. Adequate consideration should be given to achieving optimum roof pitch as ithas a significant effect on the roof cost. The selection of low roof pitch will cut down the roof cost by a greater portion particularty, where rafter exposed ceilings or insulation is used.

The roof system comprising of Asbestos cement sheet covering/Asbestos or Plywood ceiling/ 3mm thick Polyuthaleen insulation gives the lowest cost roofing system cost for a domestic roof. The cost reduction is in excess of percentage compared with the next lowest alternative.

The selection of roofing material must be based on not only the cost factor, but also on other performance factors like themal comfort, appearance etc. Such a cost model will be helpful to laymen, designers and cost advisors in advising and selection of roofing system for domestic buildings. With the use of this cost model it is planned to develop a knowledge based system that would advise on roofing system selection. This part of the research is in progress at present. 
World Wide Web is a place, which anyone can access information from anywhere in the world. A web based information dissemination method on roofing material selection is sure to bring numerous advantages to many stakeholders in the construction industry. It will be an informative decision support tool for the people involved in house construction in their decision making process on roofing material selection.

\section{REFERENCES}

Ashworth, A., (1982). Building Economics \& Cost Control Worked Solutions, 1 st edition, Butterworth \& Co Ltd, UK.

Brandon, P. S., (1987). Building Cost Modeling and Computers, E \& FN Spon Ltd, London.

Brandon, P. S. and Ferry, D. J., (1991), Cost Planning of Buildings, 6th edition, Blackwell Science Ltd, London.

Coates, D.T., (1993), Construction Materials, 1st edition, Hollen Street Press Ltd, London.

David, N.H.H., (1997), Reflective Insulation and the Control of Thermal Environments, University of Sydney.

Department of Census and Statistics, Demographic Survey 1994 Sri Lanka, Release 2.

Department of Census and Statistics, Demographic Survey 1994 Sri Lanka, Release 4.

Dias , G.V., (1999), Placing Sri Lanka on the IT Map.

Emmanuel, M.R., (1999), Effect of Roof Insulation on Indoor Thermal Environment, Senate Research Committee, University of Moratuwa, Moratuwa.

Giovni , B., (1976), Man, Climate \& Architecture, Applied Science Publication, London.

Jalyasena .H.S (2000), Construction Profile an Informative Web for Construction, Department of Building Economics, University of Moratuwa.

Koenigsberger, O. \& Lynn, R., (1965), Roofs in the Warm Humid Tropic, Lund Humphries, London.

Lakshman, K.D., (1992), A Study of Roof in TRaditional Sri Lankan Dwellings, Department of Architecture, University of Moratuwa.

Lakshan, K., (1999), Thermal Performance of Ceiling Materials, Department of Architecture, University of Moratuwa, Moratuwa.

Owen, R.E., (1985), Roofs, 1st edition, Macmillan Publishers Ltd, London.

Perera, A.A.D.A.J., (1992), Evaluation of Existing Practices of Low Cost Housing Methods, University of Moratuwa, Moratuwa.

Sri Lanka Country Paper (1988), Alternative Roofing Materials, UNIDO Regional Network in Asia for Low Cost Building Materials Technologies and Construction Systems.

Taylor, G.D., (1994), Materials in Construction, 2nd edition, Longman Science \& Technical, UK. 